\title{
Studi Hubungan antara Koefisien Determinasi dengan Kesalahan Prediksi untuk Ukuran Sampel Tertentu pada Model Bangkitan Perjalanan di Wilayah Perkotaan Gresik
}

\author{
Study of Correlation between Coefficient of Determination with \\ Prediction Error for Certain Sample Size on Trip Production Model in \\ Gresik Urban Areas
}

\author{
Dio Hananda Ziantono ${ }^{1, a)}$ \& Hitapriya Suprayitno ${ }^{2, b)}$ \\ ${ }^{1)}$ Mahasiswa Teknik Sipil, Institut Teknologi Sepuluh Nopember (ITS), Surabaya. \\ ${ }^{2)}$ Departemen Teknik Sipil, Institut Teknologi Sepuluh Nopember (ITS), Surabaya.
}

Koresponden : ${ }^{\text {a) }}$ diohananda@gmail.com, \& b) suprayitno.hita@gmail.com

\begin{abstract}
ABSTRAK
Prinsip Manajemen Aset Infrastruktur adalah dapat menilai kecukupan dan kualitas jaringan jalan. Dengan kawasan perkotaan Kabupaten Gresik berupa perindustrian, dibutuhkan pemodelan sebagai acuan karakteristik pergerakan dari suatu daerah yang membutuhkan beberapa sampel rumah tangga. Umumnya nilai $\mathrm{R}^{2}$ dipengaruhi oleh banyaknya sampel, tetapi banyaknya sampel juga dapat menghasilkan nilai $\mathrm{R}^{2}$ yang kecil juga. Maka dilakukan penelitian untuk mengetahui karakteristik perbedaan sampel. Metode yang digunakan adalah pengumpulan data primer dan sekunder. Data primer berupa survei wawancara rumah tangga untuk mendapatkan persamaan dan prediksi bangkitan perjalanan sebanyak 800 sampel. Sedangkan data sekunder berupa populasi zona dan kepemilikan sepeda motor dari Gresik Dalam Angka 2016. Hasilnya adalah rumus bangkitan perjalanan dengan a sebesar 0,9057 , b sebesar $-3,4412$, dan $\mathrm{R}^{2}$ sebesar 0,971289. Hasil prediksi bangkitan perjalanan terbesar di Randuagung dan sekitarnya sebanyak 15.756 motor/jam dan terkecil di Ngipik sebanyak 845 motor/jam. Nilai $\mathrm{R}^{2}$ pada sampel $90 \%$ B terbesar sebesar 0,971314 daripada $100 \%$ sampel. Nilai kesalahan prediksi terbesar pada sampel $90 \% \mathrm{C}$ yaitu $1,80 \%$ minimum $1,87 \%$ maksimum dan terkecil pada $90 \%$ D yaitu $0,48 \%$ minimum dan $0,55 \%$ maksimum. $90 \%$ $\mathrm{B}$ dan $90 \%$ E yang memiliki nilai $\mathrm{R}^{2}$ sebesar 0,97131 dan 0,97076 memiliki kesalahan yang lebih besar daripada $90 \%$ A dengan $\mathrm{R}^{2}$ 0,96769 dengan nilai kesalahan.
\end{abstract}

Kata Kunci : manajemen aset infrastruktur, jaringan jalan, pemodelan transportasi, bangkitan perjalanan, kesalahan prediksi, sepeda motor, perkotaan Gresik

\section{PENDAHULUAN}

Kabupaten Gresik merupakan salah satu kabupaten di Provinsi Jawa Timur. Kabupaten Gresik memiliki area yang cukup luas sebesar 1.191,25 km2. Dimana sebagian tata guna lahannya merupakan kawasan perindustrian dan juga dikenal sebagai salah satu kawasan industri utama di Provinsi Jawa Timur. Salah satu industri besar yang cukup dikenal adalah perusahaan Semen Gresik, yang merupakan perusahaan semen terbesar di Indonesia.

Setiap daerah memiliki karakteristik masing-masing untuk tingkat bangkitan-tarikan perjalanannya dari yang hanya tidak padat hingga padat sekali. Karakteristik tersebut dipengaruhi oleh jenis tata guna lahan daerah tersebut, dimana apabila hanya daerah pinggiran kota maupun desa, bangkitan-tarikan perjalanannya sedikit dan apabila tata guna 
lahannya berupa pertokoan, industri, atau perkantoran maka daerah tersebut akan mengalami bangkitan-tarikan perjalanan yang padat.

Jaringan jalan selalu dikelola dengan prinsip Manajemen Aset Infrastruktur yang harus dikembangkan untuk prediksi sepuluh tahun ke depan. Maka diperlukan suatu pemodelan dimana infrastrukturnya mengikuti tujuh ilmu dasar seperti infrastruktur, fungsi infrastruktur, struktur fisik infrastruktur, eksternalitas infrastruktur, siklus kehidupan infrastruktur, ekonomi infrastruktur, dan mengelola penyusunan infrastruktur (Suprayitno \& Soemitro, 2018).

Pemodelan adalah pencerminan dan penyederhanaan realita. Semakin mencerminkan realita, maka dapat dikatakan pemodelan tersebut menjadi semakin baik (Tamin, 2000). Dalam merencanakan prasarana transportasi ini perlu adanya sebuah pemodelan dimana pemodelan ini dapat digunakan sebagai acuan untuk mewakili karakteristik perjalanan dimana per individu memiliki tempat tujuan yang berbeda-beda dari setiap daerah yang diteliti. Agar dapat menghasilkan pemodelan yang layak maka perlu dicari bangkitan perjalanan terlebih dahulu. Untuk mendapatkan bangkitan perjalanan tersebut, terdapat bermacam-macam kriteria yang perlu diteliti salah satunya seperti jumlah anggota keluarga, jumlah kepemilikan kendaraan, jumlah perjalanan yang dilakukan per orangnya, hingga tempat yang akan dituju per individu. Dengan adanya alasan tersebut, perlu adanya pengambilan sampel yang dapat menjadi data yang valid untuk menciptakan model bangkitan perjalanannya.

Dalam pemodelan transportasi, pada umumnya nilai koefisien determinasi $\left(\mathrm{R}^{2}\right)$ digunakan sebagai ukuran bagus atau tidaknya suatu model karena semakin banyak sampel, maka semakin bagus nilai $\mathrm{R}^{2}$ nya. Sebelumnya telah diteliti bahwa dengan jumlah sampel rumah tangga yang sedikit dapat menghasilkan nilai $\mathrm{R}^{2}$ yang baik pula (Suprayitno \& Ratnasari, 2017). Penelitian tersebut hanya menggunakan sampel rumah tangga yang sedikit saja untuk mengidentifikasi karakteristik $\mathrm{R}^{2}$, maka untuk menyempurnakan penelitian tersebut, dilakukan sebuah penelitian yang menggunakan data sesungguhnya di lapangan berupa 800 sampel rumah tangga di kawasan perkotaan Kabupaten Gresik.

\section{STUDI PUSTAKA}

\section{Bangkitan dan Tarikan Perjalanan}

Bangkitan perjalanan adalah tahapan pemodelan yang memperkirakan jumlah perjalanan yang berasal dari suatu zona atau tata guna lahan dan jumlah perjalanan yang tertarik ke suatu tata guna lahan atau zona. Pergerakan lalu lintas merupakan fungsi tata guna lahan yang menghasilkan pergerakan lalu lintas (Tamin, 2000). Bangkitan lalu lintas ini mencakup:

- Lalu lintas yang meninggalkan suatu lokasi

- Lalu lintas yang menuju atau tiba ke suatu lokasi

Bangkitan dan tarikan perjalanan dapat dilihat secara diagram pada gambar 1. (Wells, 1975)

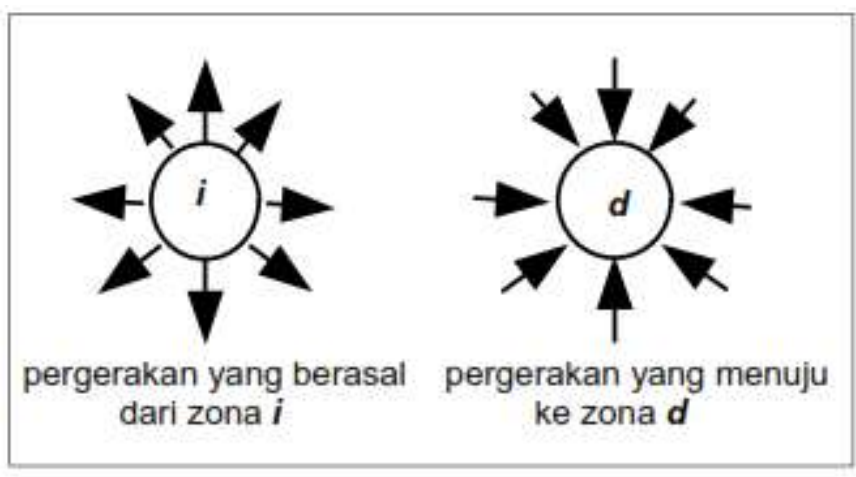

Gambar 1. Ilustrasi Bangkitan dan Tarikan Perjalanan 
Model yang baik merupakan model yang dapat menggambarkan semua faktor yang mewakili karateristik perilaku manusia. Akan tetapi, kemampuan pemodelan yang dibatasi waktu dan biaya menyebabkan sulitnya menghasilkan model yang lengkap. Secara praktis dibutuhkan berbagai macam jenis model untuk berbagai tujuan dan pemecahan permasalahan tertentu. Konsep perencanaan transportasi yang telah berkembang saat ini dan yang paling popular adalah Model Perencanaan Transportasi Empat Tahap. Adapun tahap dari model tersebut adalah Trip Generation, Modal Split, Trip Distribution dan Trip Assignment. Dalam suatu pembuatan model terdapat beberapa hal yang sangat mempengaruhi tingkat keberhasilan, yaitu penentuan zona dan jumlah sampel (Tamin, 2008).

Trip Generation dibagi menjadi dua yaitu Trip Production dan Trip Attraction. Dalam penelitian ini membahas tentang Trip Production (Bangkitan Perjalanan) yang digolongkan menjadi tiga tipe dasar yaitu model regresi zona, model analisis kategori, dan model regresi rumah tangga. Dari tipe-tipe tersebut, yang sering digunakan dalam kasus profesional yaitu model regresi zona (ZR) dan regresi linear (LR) merupakan model regresi zona yang paling digunakan saat ini (Suprayitno \& Ratnasari, 2017).

\section{Survei Wawancara Rumah Tangga}

Survei rumah tangga merupakan salah satu metode yang paling sering digunakan untuk mencari karakteristik perjalanan dengan cara survei wawancara rumah tangga yang terdiri dari beberapa informasi yang sangat dibutuhkan, yaitu anggota keluarga, usia dan jenis kelamin, pekerjaan, pendapatan, pemilikan kendaraan, dan intensitas pergerakan yang dilakukan setiap harinya oleh seluruh anggota keluarga. Tambahan lainnya dalam survei rumah tangga juga bisa dinyatakan karakteristik pergerakan, misalnya jenis tata guna lahan zona asal dan zona tujuan, waktu berangkat dan tiba, tujuan pergerakan, dan moda transportasi yang digunakan. Pengambilan sampel 100\% sangatlah tidak mungkin karena membutuhkan biaya yang sangat besar, tenaga kerja yang sangat banyak, dan waktu proses yang sangat lama (Tamin, 2000).

\section{Model Bangkitan Perjalanan}

Perhitungan bangkitan perjalanan menggunakan persamaan regresi perjalanan sepeda motor yang dibentuk dari hubungan antara data jumlah kepemilikan sepeda motor dengan data jumlah perjalanan sepeda motor di wilayah kota Samarinda yang didapatkan dari survei rumah tangga (Household Interview Survey). Untuk membuat persamaan bangkitan perjalanan (trip production), perlu adanya grafik hubungan antara jumlah kepemilikan sepeda motor dengan jumlah perjalanan berupa analisis grafik linear. Dari analisis regresi linear diketahui bahwa semakin banyak jumlah sepeda motor maka semakin banyak jumlah perjalanan yang terjadi. Berikut merupakan grafik hubungan regresi linear dengan rincian $\mathrm{TP}_{\mathrm{SM}}=0,9372+3,3986$ dan $\mathrm{R}^{2}=0,9658$ yang ditunjukkan pada gambar 2 (Praditya, 2017). 


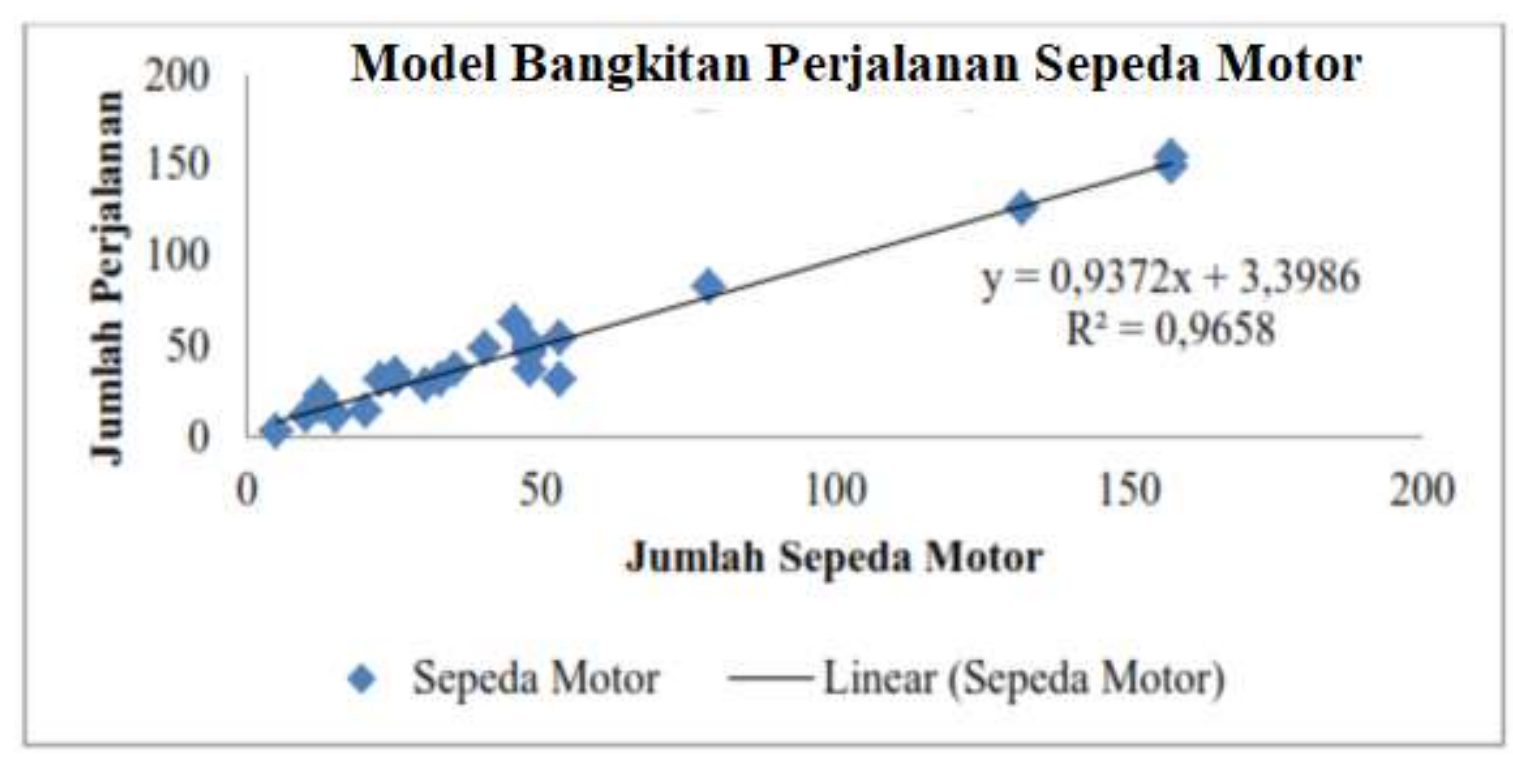

Gambar 2. Grafik Model Bangkitan Perjalanan Sepeda Motor Sumber : Praditya, 2017

\section{PENGUMPULAN DATA}

Metode yang digunakan pada perhitungan Bangkitan Perjalanan ini adalah dengan pengumpulan data primer berupa survei wawancara rumah tangga yang berisikan data populasi rumah tangga, kepemilikan kendaraan sepeda motor, dan jumlah perjalanan menggunakan kendaraan sepeda motor. Sedangkan data sekunder merupakan data jumlah kepemilikan kendaraan sepeda motor dan populasi yang ada di kawasan perkotaan Kabupaten Gresik. Dari pengolahan data primer dan data sekunder tersebut akan menghasilkan persamaan bangkitan perjalanan (trip production) yang kemudian digunakan untuk menghitung jumlah prediksi bangkitan perjalanan kendaraan sepeda motor.

\section{ANALISIS PENELITIAN}

\section{Hasil Survei Rumah Tangga}

Survei rumah tangga yang dilakukan dengan wawancara per rumah tangga dihasilkan jumlah data 800 sampel yang dilakukan pada 25 zona. Adapun data yang digunakan dari survei tersebut untuk perhitungan bangkitan perjalanan (trip production) adalah sebagai berikut : 1). Jumlah populasi rumah tangga, 2). Jumlah kepemilikan sepeda motor, dan 3). Jumlah perjalanan yang dilakukan menggunakan sepeda motor. Dari data tersebut dihasilkan berupa rangkuman yang ditunjukkan pada Tabel 1 . 
Tabel 1. Hasil Survei Rumah Tangga

\begin{tabular}{|c|c|c|c|c|c|c|}
\hline \multirow[b]{2}{*}{ No. } & \multirow[b]{2}{*}{ Kecamatan } & \multirow[b]{2}{*}{ Zona } & \multirow[b]{2}{*}{$\begin{array}{l}\text { Rumah } \\
\text { Tangga }\end{array}$} & \multicolumn{3}{|c|}{ Data Rumah Tangga } \\
\hline & & & & Populasi & $\begin{array}{c}\text { Jumlah } \\
\text { Kepemilikan } \\
\text { Sepeda } \\
\text { Motor }\end{array}$ & $\begin{array}{l}\text { Jumlah } \\
\text { Perjalanan }\end{array}$ \\
\hline 1 & \multirow{10}{*}{$\begin{array}{c}\text { Kecamatan } \\
\text { Gresik }\end{array}$} & Ngipik & 7 & 19 & 12 & 9 \\
\hline 2 & & Tlogopojok & 13 & 40 & 26 & 23 \\
\hline 3 & & Sidorukun & 2 & 7 & 3 & 3 \\
\hline 4 & & Kramatinggil & 1 & 3 & 2 & 2 \\
\hline 5 & & Karang & 25 & 79 & 31 & 39 \\
\hline 6 & & Lumpur dsk & 33 & 102 & 59 & 55 \\
\hline 7 & & Pulopancikan dsk & 5 & 12 & 8 & 7 \\
\hline 8 & & Trate dsk & 17 & 51 & 32 & 24 \\
\hline 9 & & Sukorame dsk & 21 & 65 & 41 & 34 \\
\hline 10 & & Sidokumpul dsk & 78 & 302 & 159 & 141 \\
\hline 11 & \multirow{10}{*}{$\begin{array}{c}\text { Kecamatan } \\
\text { Kebomas }\end{array}$} & Dahanrejo & 6 & 16 & 11 & 9 \\
\hline 12 & & Kembangan & 35 & 110 & 63 & 54 \\
\hline 13 & & Kedanyang & 2 & 6 & 4 & 2 \\
\hline 14 & & Indro & 2 & 7 & 4 & 2 \\
\hline 15 & & Giri dsk & 39 & 123 & 80 & 63 \\
\hline 16 & & Randuagung dsk & 124 & 420 & 251 & 218 \\
\hline 17 & & Prambangan dsk & 5 & 16 & 17 & 11 \\
\hline 18 & & Sidomoro & 49 & 158 & 113 & 79 \\
\hline 19 & & Segoromadu dsk & 5 & 18 & 13 & 9 \\
\hline 20 & & Singosari dsk & 29 & 114 & 58 & 54 \\
\hline 21 & \multirow{5}{*}{$\begin{array}{c}\text { Kecamatan } \\
\text { Manyar }\end{array}$} & Suci & 172 & 584 & 244 & 253 \\
\hline 22 & & Yosowilangun & 66 & 230 & 151 & 105 \\
\hline 23 & & Pongangan & 39 & 151 & 85 & 67 \\
\hline 24 & & Romoo & 6 & 18 & 14 & 7 \\
\hline 25 & & Sukomulyo & 19 & 77 & 53 & 36 \\
\hline \multicolumn{3}{|c|}{ Total } & 800 & 2728 & 1534 & 1306 \\
\hline
\end{tabular}

\section{Pemodelan Bangkitan Perjalanan Sepeda Motor}

Dari data-data diatas kemudian dilakukan perhitungan untuk mendapatkan persamaan bangkitan perjalanan (trip production). Perhitungan bangkitan perjalanan untuk kendaraan sepeda motor, hubungan yang digunakan adalah jumlah kendaraan sepeda motor dan jumlah perjalanan kendaraan sepeda motor yang didapat dari data survei wawancara rumah tangga. Hasil grafik persamaan bangkitan perjalanan dapat dilihat pada gambar 3. 


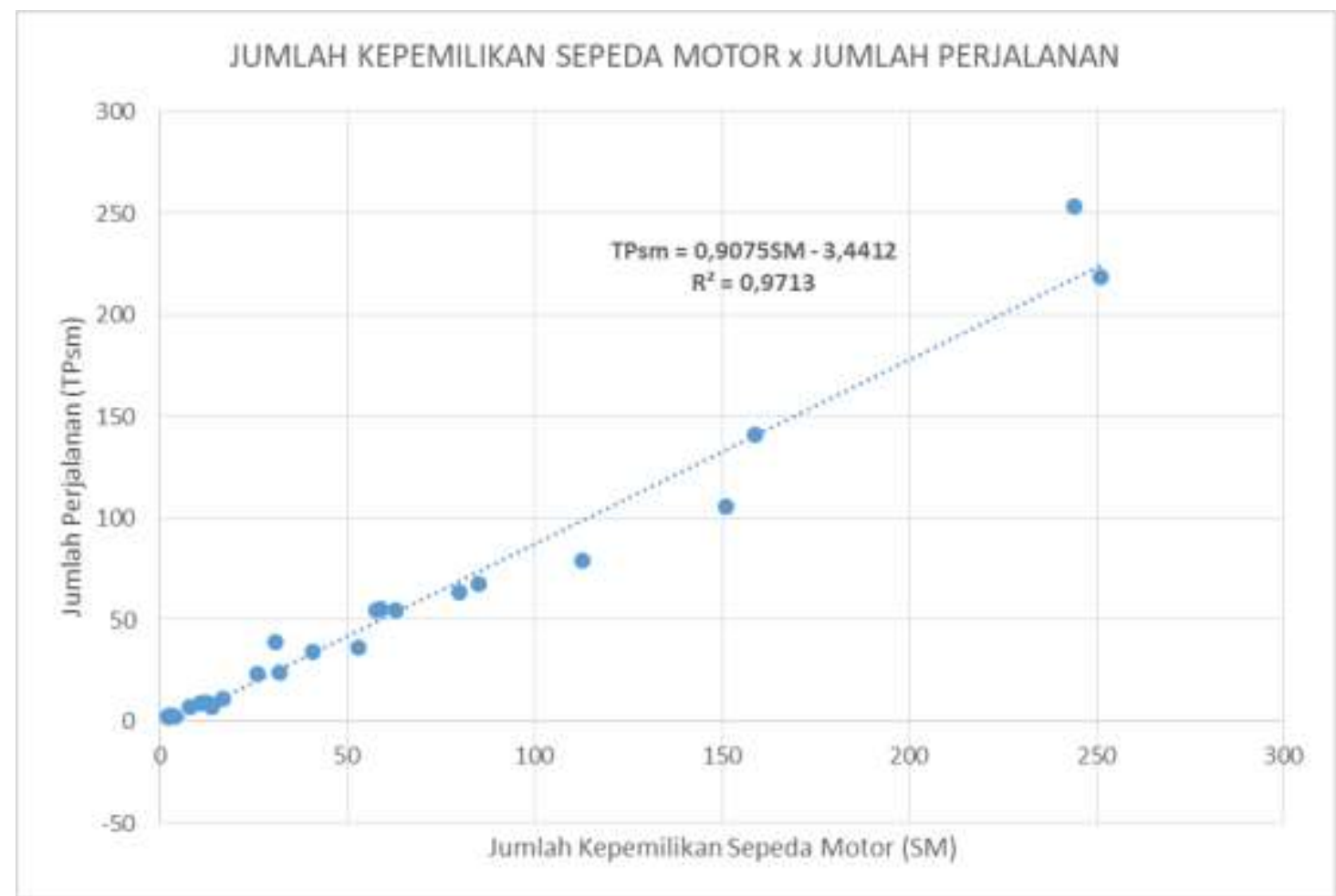

Gambar 3. Grafik Bangkitan Perjalanan Sepeda Motor

$$
\begin{array}{ll}
\mathrm{y} & =\mathrm{a} \times \mathrm{x}+\mathrm{b} \\
\mathrm{TP}_{\mathrm{SM}} & =0,9075 \times S M-3,441 \\
\mathrm{R}^{2} & =0,9713
\end{array}
$$

Dimana :

$\mathrm{TP}_{\mathrm{SM}}=$ Prediksi Bangkitan Perjalanan Kendaraan Sepeda Motor

SM = Jumlah Sepeda Motor

$\mathrm{R}^{2} \quad=$ Koefisien Determinasi

Berdasarkan grafik bangkitan perjalanan sepeda motor diatas dapat diketahui bahwa semakin banyak jumlah kepemilikan sepeda motor maka semakin banyak jumlah perjalanan yang terjadi menggunakan kendaraan sepeda motor. Persamaan yang dihasilkan yaitu $\mathrm{TP}_{\mathrm{SM}}=$ $0,9075^{*} \mathrm{SM}-3,4412$ dengan nilai $\mathrm{R}^{2}=0,9713$.

\section{Perhitungan Bangkitan Perjalanan}

Perhitungan bangkitan perjalanan (trip production) menggunakan persamaan regresi linier yang telah ditunjukkan pada Gambar 3 berupa grafik bangkitan perjalanan yang menghasilkan prediksi bangkitan perjalanan kendaraan sepeda motor. Dalam perhitungan bangkitan perjalanan, jumlah kepemilikan sepeda motor berpengaruh terhadap jumlah bangkitan perjalanannya. Semakin banyak jumlah kepemilikan sepeda motor dalam suatu zona, maka semakin besar pula jumlah bangkitan perjalanan dalam zona tersebut. Berikut ini merupakan hasil perhitungan bangkitan perjalanan yang ditunjukkan pada Tabel 2. 
Tabel 2. Hasil Bangkitan Perjalanan

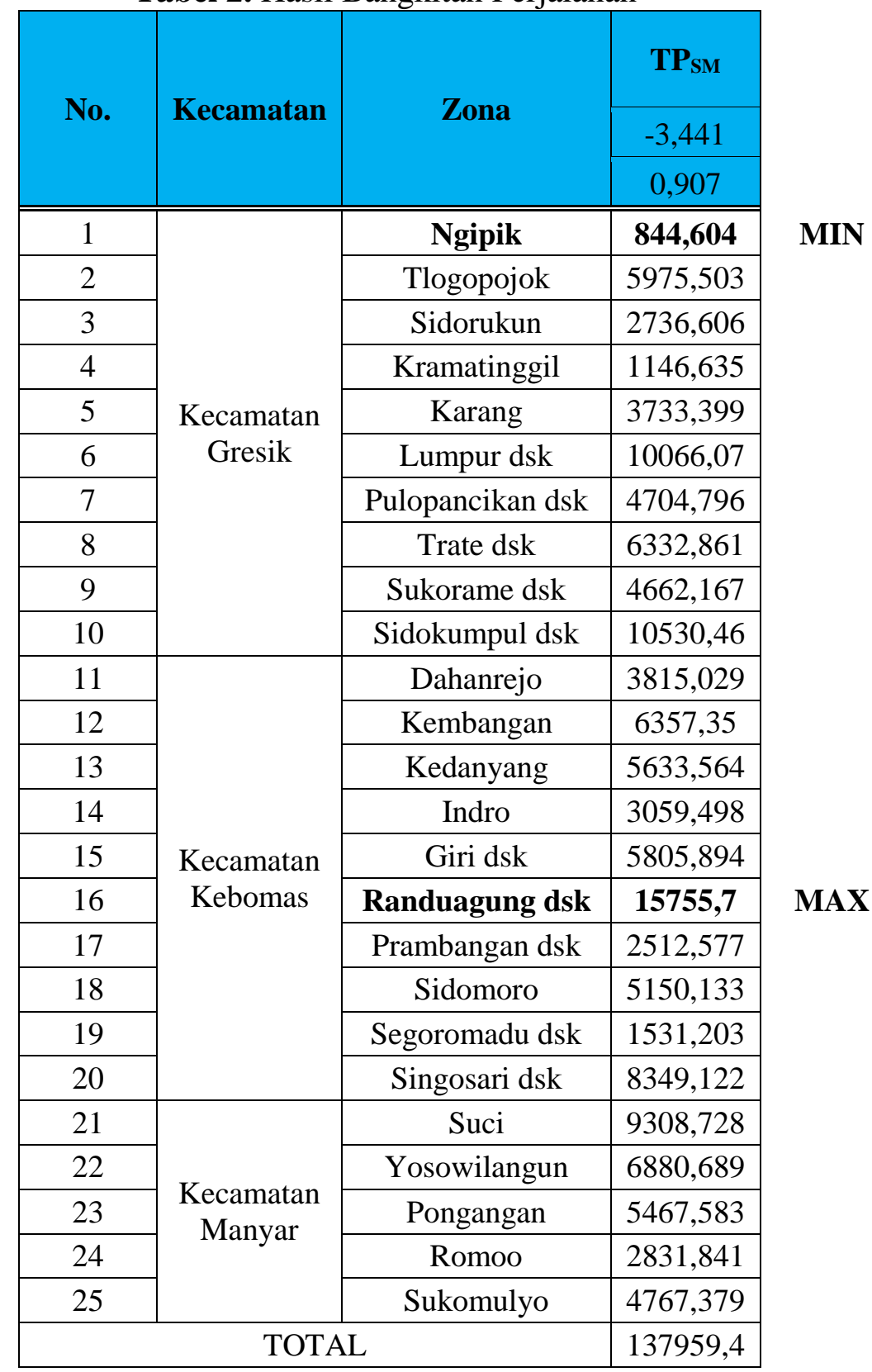

\section{Pengaruh Ukuran Sampel}

Dalam pemodelan transportasi, penentuan banyaknya sampel dalam suatu penelitian merupakan hal yang sangat penting karena menyebabkan perbedaan karakteristik dimana pada umumnya semakin sedikit sampel yang diambil maka semakin besar faktor kesalahannya. Dari perbedaan karakteristik tersebut, selain dapat dilihat dari perbedaan hasil terhadap prediksi bangkitan perjalanan dapat juga dilihat dari persamaan bangkitan perjalanannya juga. Berikut merupakan karakteristik-karakteristik akibat pengurangan sampel yang ditunjukkan pada Tabel 3. 
Tabel 3. Perbedaan Rumus, $\mathrm{R}^{2}$, Prediksi Trip Production, dan Error Prediksi akibat perbedaan sampel

\begin{tabular}{|c|c|c|c|c|c|c|}
\hline Ukuran & \multirow{2}{*}{$\begin{array}{c}\text { Rumus } \\
\text { Sampel }\end{array}$} & \multirow{2}{*}{$\mathbf{R}^{2}$} & \multicolumn{2}{c|}{ Prediksi Trip Production } & \multicolumn{2}{c|}{ Error Prediksi } \\
\cline { 4 - 7 } & & MIN & MAX & MIN & MAX \\
\hline $100 \%$ & $0,907 \mathrm{SM}-3,441$ & 0,97129 & 844,604 & 15755,684 & $0,00 \%$ & $0,00 \%$ \\
\hline $90 \%$ A & $0,913 \mathrm{SM}-4,156$ & 0,96769 & 849,499 & 15859,219 & $0,58 \%$ & $0,66 \%$ \\
\hline $90 \% \mathrm{~B}$ & $0,916 \mathrm{SM}-3,927$ & 0,97131 & 852,533 & 15911,573 & $0,94 \%$ & $0,99 \%$ \\
\hline $90 \% \mathrm{C}$ & $0,924 \mathrm{SM}-4,158$ & 0,96858 & 859,782 & 16050,342 & $1,80 \%$ & $1,87 \%$ \\
\hline $90 \% \mathrm{D}$ & $0,912 \mathrm{SM}-4,054$ & 0,96892 & 848,666 & 15841,946 & $0,48 \%$ & $0,55 \%$ \\
\hline $90 \% \mathrm{E}$ & $0,917 \mathrm{SM}-3,973$ & 0,97076 & 853,422 & 15928,902 & $1,04 \%$ & $1,10 \%$ \\
\hline
\end{tabular}

Dari data-data diatas dapat digambarkan dalam bentuk grafik regresi linear dengan masing-masing sampel yang ditunjukkan pada gambar 4 berikut ini.

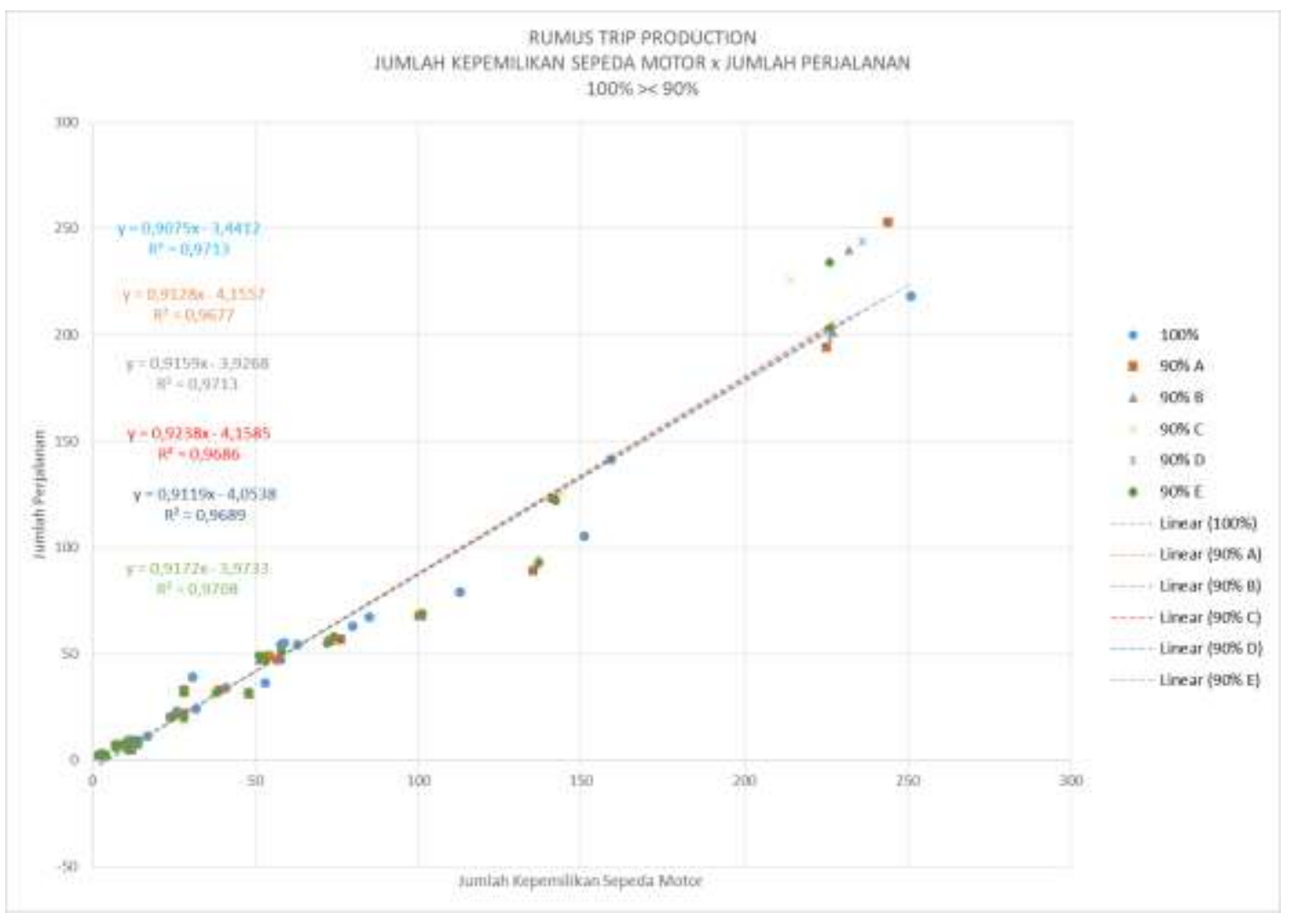

Gambar 4. Grafik Rumus Bangkitan Perjalanan Sepeda Motor 100\% dengan variasi 90\% sampel

Dari gambar di atas dapat dilihat bahwa garis regresi linear variasi sampel $90 \%$ tidak segaris dengan garis regresi linear sampel $100 \%$. Dan juga nilai $\mathrm{R}^{2}$ terbesar bila dibandingkan dengan sampel yang lain, sampel $90 \%$ B dengan nilai 0,971314 sedangkan nilai $\mathrm{R}^{2}$ yang terkecil bila dibandingkan dengan ukuran sampel yang lain, sampel $90 \%$ A dengan nilai 0,967688. Apabila melihat gambar garis regresi dari grafik diatas, dapat diketahui bahwa garis regresi tidak segaris dengan garis sampel 100\% (800 sampel) karena adanya perbedaan pengambilan sampel. Setelah mendapatkan nilai $\mathrm{R}^{2}$, dari nilai prediksi bangkitan perjalanan 
dari masing-masing sampel $90 \%$ dilakukan selisih dengan nilai prediksi dari sampel $100 \%$ untuk mengetahui kesalahan prediksi akibat perbedaan sampel. Perbedaan tersebut ditunjukkan pada gambar 5 dan gambar 6 berikut ini.

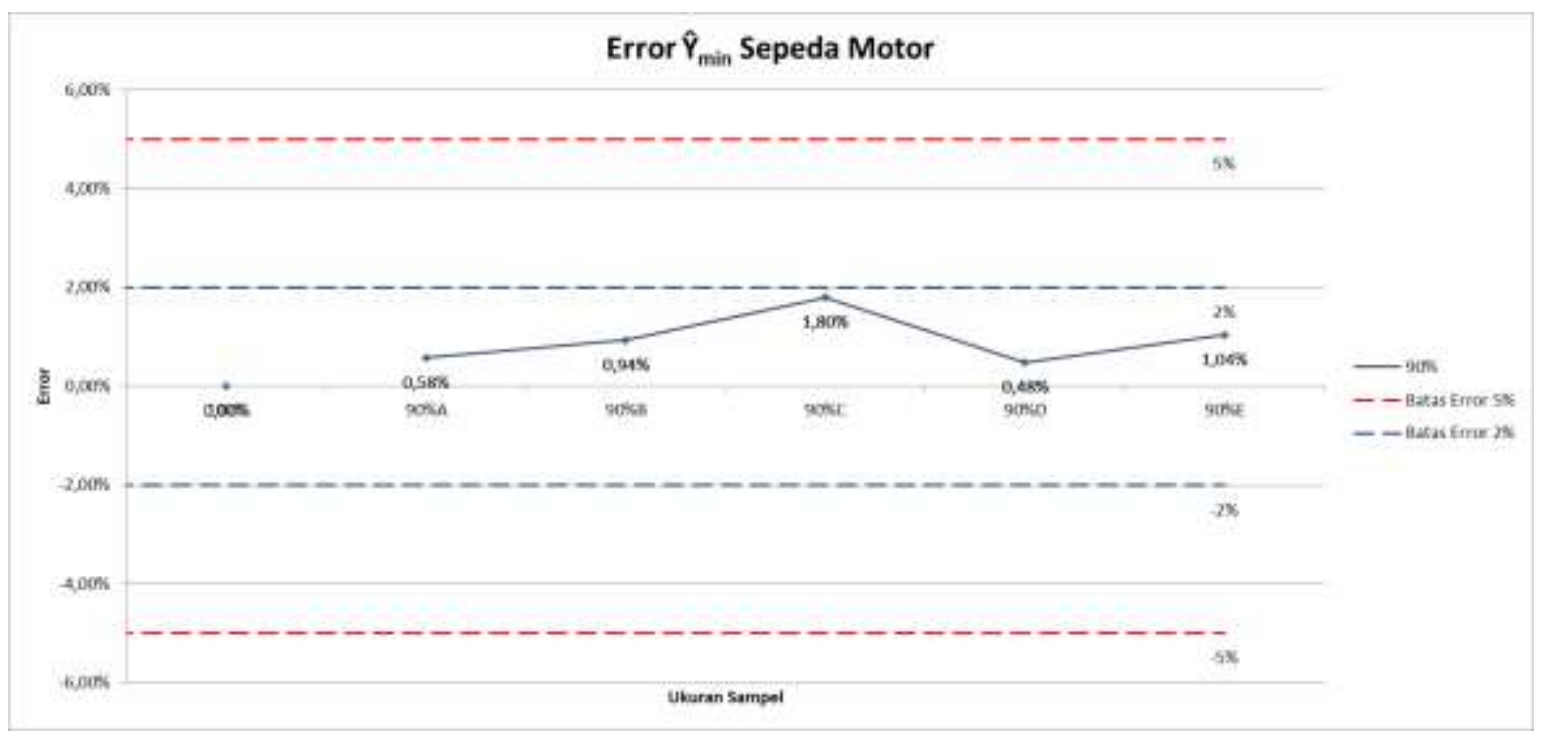

Gambar 5. Kesalahan Prediksi Bangkitan Perjalanan akibat dari Perbedaan Sampel untuk Kepemilikan Kendaraan Minimum

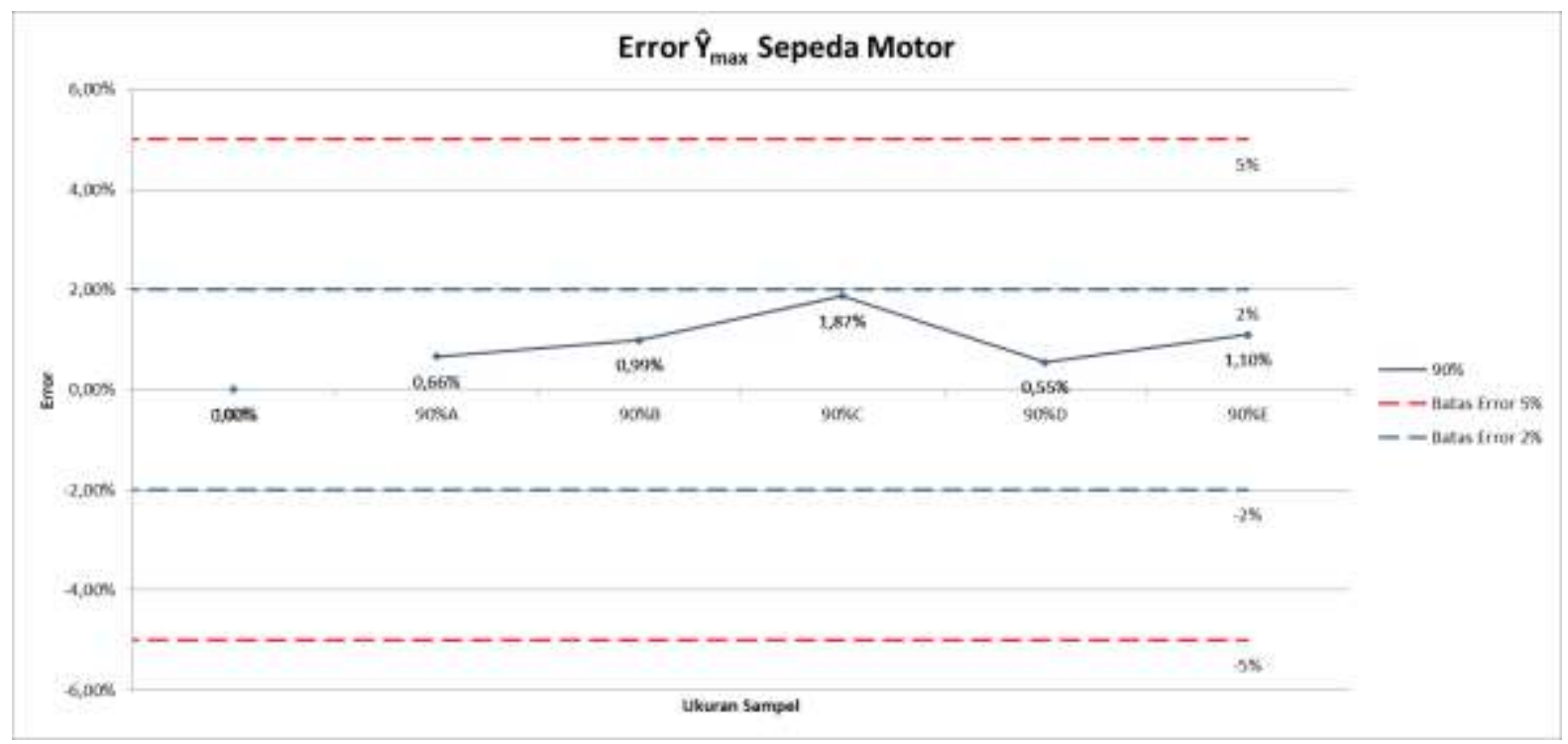

Gambar 6. Kesalahan Prediksi Bangkitan Perjalanan akibat dari Perbedaan Sampel untuk Kepemilikan Kendaraan Maksimum

Dari gambar 5 dan gambar 6 terdapat perbandingan nilai error terbesar pada sampel $90 \% \mathrm{C}$ sebesar $1,80 \%$ dan terkecil pada $90 \%$ D sebesar $0,48 \%$ untuk trip production sepeda motor minimum dan pada sampel $90 \% \mathrm{C}$ sebesar 1,87\% untuk yang terbesar dan $90 \% \mathrm{D}$ sebesar $0,55 \%$ untuk trip production sepeda motor maksimum. Dari gambar diatas dapat disimpulkan bahwa pengurangan sampel menyebabkan kesalahan prediksi yang apabila melewati batas error tertentu maka dapat mengurangi tingkat keakuratan sampel tersebut. Kemudian dengan data-data yang telah didapat dicari karakteristik hubungan $\mathrm{R}^{2}$ dengan nilai kesalahan prediksinya yang ditunjukkan pada gambar 7 dan gambar 8 berikut. 


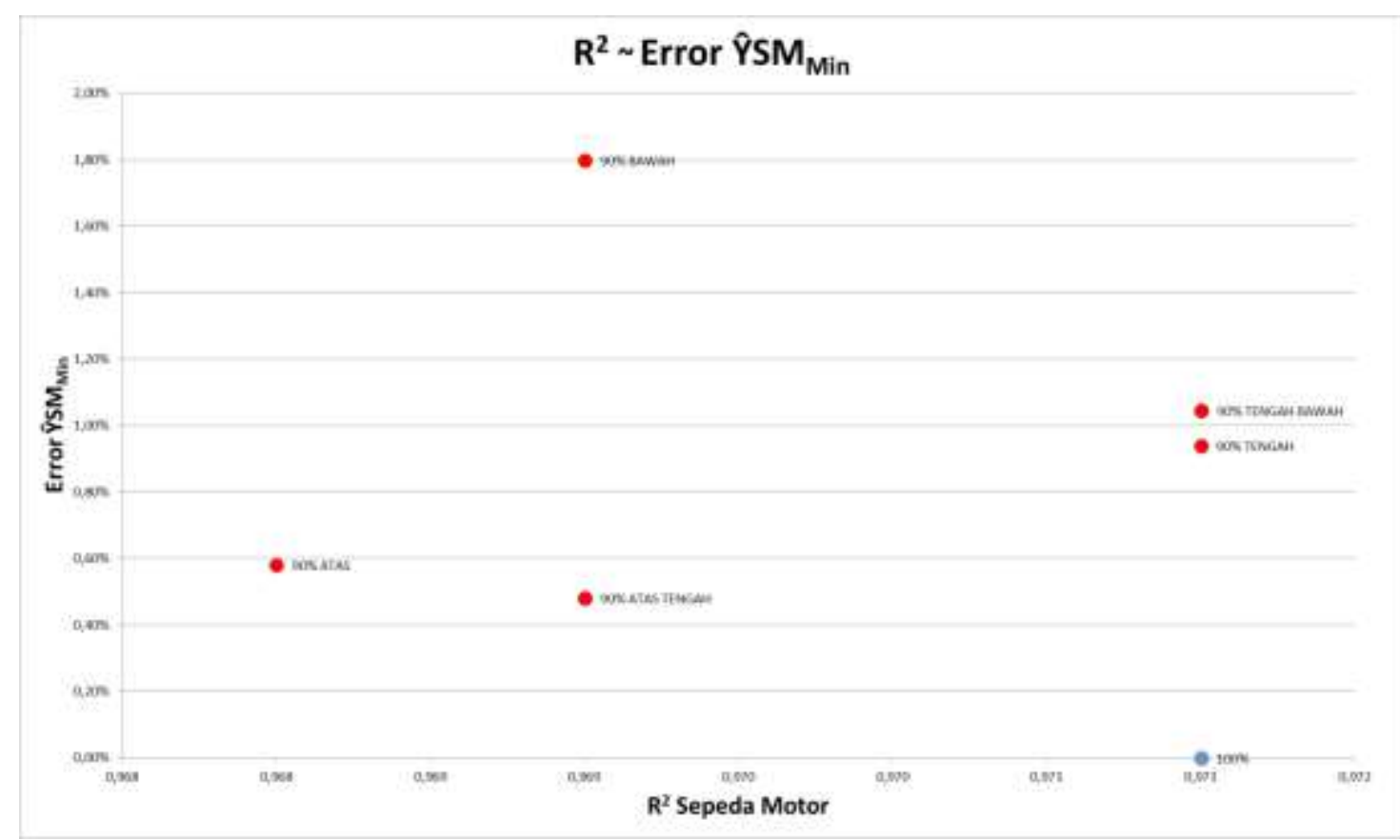

Gambar 7. Grafik korelasi antara nilai $\mathrm{R}^{2}$ dengan kesalahan prediksi trip production sepeda motor minimum

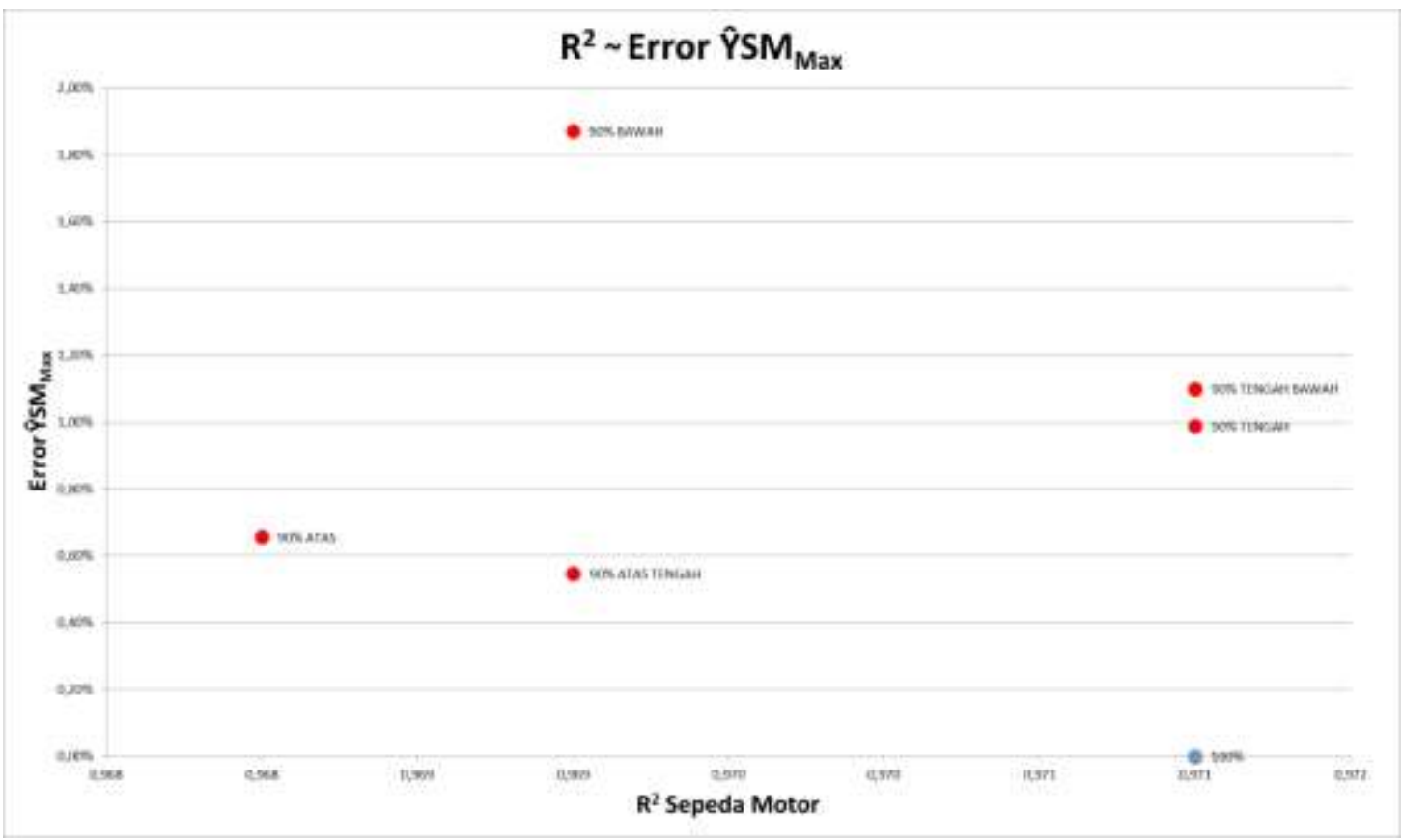

Gambar 8. Grafik korelasi antara nilai $\mathrm{R}^{2}$ dengan kesalahan prediksi trip production sepeda motor maksimum

Seharusnya semakin besar nilai $\mathrm{R}^{2}$ nya, semakin kecil tingkat kesalahan prediksinya karena semakin besar $\mathrm{R}^{2}$ nya semakin bagus sampelnya. Tetapi dari gambar 7 dan 8 diatas dapat diketahui bahwa nilai $\mathrm{R}^{2}$ yang besar dapat memiliki nilai kesalahan yang besar juga yaitu pada sampel $90 \% \mathrm{~B}$ dan $90 \% \mathrm{E}$ dengan nilai $\mathrm{R}^{2}$ masing-masing 0,97131 dan 0,97076 memiliki nilai kesalahan sebesar $0,94 \%$ dan $1,04 \%$ yang lebih besar apabila dibandingkan dengan sampel $90 \%$ A dengan $\mathrm{R}^{2} 0,96769$ tetapi hanya memiliki nilai kesalahan $0,58 \%$ untuk kepemilikan sepeda motor minimum. Begitu juga dengan data kepemilikan sepeda motor 
maksimum 90\% B dan 90\% E yang memiliki nilai $\mathrm{R}^{2}$ masing-masing 0,97131 dan 0,97076 memiliki nilai kesalahan sebesar $0,99 \%$ dan $1,10 \%$ yang lebih besar apabila dibandingkan dengan sampel 90\% A dengan $\mathrm{R}^{2} 0,96769$ tetapi hanya memiliki nilai kesalahan $0,66 \%$. Maka dapat disimpulkan bahwa nilai $\mathrm{R}^{2}$ yang besar belum tentu selalu akurat karena tergantung pada nilai kesalahannya, semakin besar kesalahannya maka sampel tersebut tidak dapat digunakan.

\section{KESIMPULAN}

Proses perhitungan bangkitan perjalanan dan pengaruh ukuran perbedaan sampel menghasilkan beberapa hal sebagai berikut :

- Menghasilkan rumus bangkitan perjalanan $\left(\mathrm{TP}_{\mathrm{SM}}\right)$ dengan nilai a sebesar 0,9057 dengan nilai $\mathrm{b}$ sebesar $-3,4412$ dan nilai $\mathrm{R}^{2}=0,97129$

- Total prediksi bangkitan perjalanan sejumlah 137.959 motor/jam, dengan hasil terbesar di zona Randuagung dan sekitarnya yaitu 15.756 motor/jam dan hasil terkecil di zona Ngipik yaitu 845 motor/jam.

- Dari perbandingan terhadap ukuran sampel didapatkan nilai $\mathrm{R}^{2}$ pada ukuran sampel $90 \%$ B lebih besar daripada ukuran sampel 100\% sebesar 0,97131 daripada 0,97129 walaupun sampel $90 \%$ B memiliki sampel lebih sedikit.

- Nilai kesalahan prediksi terbesar terdapat pada zona dengan sampel $90 \%$ C yaitu $1,80 \%$ dan terkecil pada sampel $90 \%$ D sebesar $0,48 \%$ untuk kepemilikan sepeda motor minimum

- Nilai kesalahan prediksi terbesar terdapat pada zona dengan sampel $90 \%$ C yaitu $1,87 \%$ dan terkecil pada sampel $90 \% \mathrm{D}$ sebesar $0,55 \%$ untuk kepemilikan sepeda motor maksimum

- Ukuran sampel $90 \%$ B dan $90 \%$ E dengan nilai $\mathrm{R}^{2}$ sebesar 0,97131 dan 0,97076 memiliki nilai kesalahan sebesar $0,94 \%$ dan 1,04\% lebih besar daripada sampel $90 \%$ A yang memiliki nilai $\mathrm{R}^{2}$ lebih kecil sebesar 0,96769 dengan nilai kesalahan sebesar 0,58\% untuk kepemilikan sepeda motor minimum

- Ukuran sampel 90\% B dan 90\% E dengan nilai $\mathrm{R}^{2}$ sebesar 0,97131 dan 0,97076 memiliki nilai kesalahan sebesar $0,99 \%$ dan 1,10\% lebih besar daripada sampel $90 \%$ A yang memiliki nilai $\mathrm{R}^{2}$ lebih kecil sebesar 0,96769 dengan nilai kesalahan sebesar 0,66\% untuk kepemilikan sepeda motor minimum

- Dapat disimpulkan bahwa tidak selalu sampel dengan nilai $\mathrm{R}^{2}$ yang besar berarti memiliki prediksi yang lebih akurat daripada sampel dengan $\mathrm{R}^{2}$ yang lebih kecil.

CATATAN. Penelitian ini dilakukan dengan survei dan pengamatan secara langsung di jam puncak pagi yaitu pada jam $06.00-09.00$ WIB. Hasil pengamatan dijadikan dasar dalam asumsi proporsi kuat tarik sebagian besar adalah berangkat sekolah dan bekerja.

\section{DAFTAR PUSTAKA}

Praditya, N.D.A. (2016). "Pemodelan Transportasi Moda Sepeda Motor Kota Samarinda Untuk Tahun 2016". Tesis Magister Manajemen Rekayasa Transportasi. Institut Teknologi Sepuluh Nopember. Surabaya.

Suprayitno, H. \& Praditya, N.D.A. (2018) "Model Bangkitan Perjalanan Kota Samarinda Berbasis Zona Kecamatan”. Jurnal GEMA AKTUALITA. Vol. 7, No. 1:23-28.

Suprayitno, H. \& Ratnasari, V. (2017), "Reflexion on Linear Regression Trip Production Modelling Method for Ensuring Good Model Quality", AIP Conference Proceedings 1903, 060013 (2017).

Suprayitno, H. \& Soemitro, R.A.A. (2018). "Preliminary Reflexion on Basic Principle of Infrastructure Asset Management”. Jurnal Manajemen Aset Infrastruktur dan Fasilitas. Vol. 2, No. 1 Maret 2018, pp : 1-9. 
(e)ISSN 2615-1847 (p)ISSN 2615-1839

Jurnal Manajemen Aset Infrastruktur \& Fasilitas - Vol. 2, No.2, September 2018

Tamin, O.Z. (2000). Perencanaan \& Pemodelan Transportasi, Edisi Kedua, Institut Teknologi Bandung, Bandung 